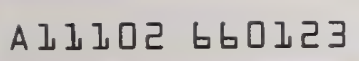

NATLL INST OF STAND \& TECH

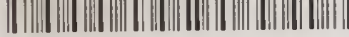

Alliab 0537ьв $\mathbf{3 4 5 1}$

\title{
Fire Growth in Combat Ships
}

John A. Rockett

U.S. DEPARTMENT OF COMMERCE

National Bureau of Standards

Center for Fire Research

Gaithersburg, MD 20899

September 1986

$Q C$

$d$ in part by:

100

ivid Taylor Naval Ship

.456 sh and Development Center 

NBSIR 86-3451

\section{FIRE GROWTH IN COMBAT SHIPS}

John A. Rockett

U.S. DEPARTMENT OF COMMERCE

National Bureau of Standards

Center for Fire Research

Gaithersburg, MD 20899

September 1986

Supported in part by:

U.S. David Taylor Naval Ship

Research and Development Center

Washington, DC

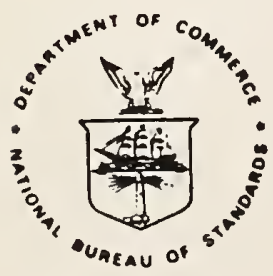

U.S. DEPARTMENT OF COMMERCE, Malcolm Baldrige, Secretary NATIONAL BUREAU OF STANDARDS, Ernest Ambler, Director 



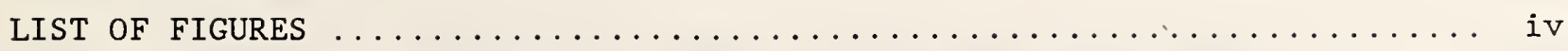

LIST of SYMBOLS $\ldots \ldots \ldots \ldots \ldots \ldots \ldots \ldots \ldots \ldots \ldots \ldots \ldots \ldots \ldots \ldots \ldots \ldots \ldots$

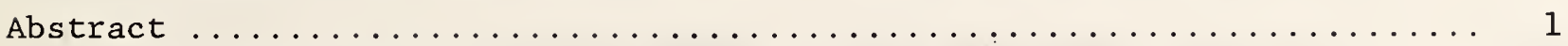

EXECUTIVE SUMMARY AND RECOMMENDATIONS $\ldots \ldots \ldots \ldots \ldots \ldots \ldots \ldots \ldots \ldots$

INTRODUCTION $\ldots \ldots \ldots \ldots \ldots \ldots \ldots \ldots \ldots \ldots \ldots \ldots \ldots \ldots \ldots \ldots \ldots \ldots \ldots \ldots \ldots \ldots$

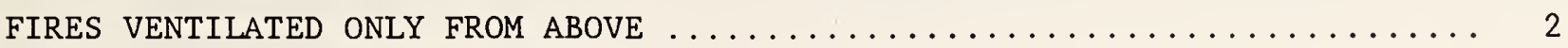

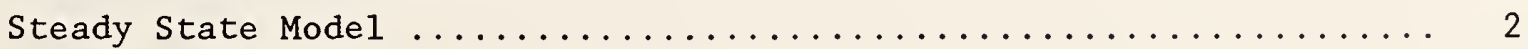

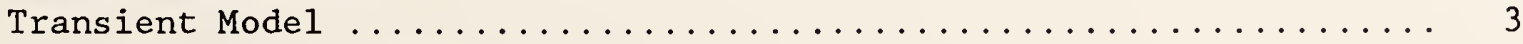

PREDICTION OF FIRE GROWTH RATES $\ldots \ldots \ldots \ldots \ldots \ldots \ldots \ldots \ldots \ldots \ldots \ldots \ldots \ldots \ldots$

Exponentially Growing Fires $\ldots \ldots \ldots \ldots \ldots \ldots \ldots \ldots \ldots \ldots \ldots \ldots$

SPREAD OF SMOKE AND TOXIC GAS $\ldots \ldots \ldots \ldots \ldots \ldots \ldots \ldots \ldots \ldots \ldots \ldots \ldots \ldots \ldots$

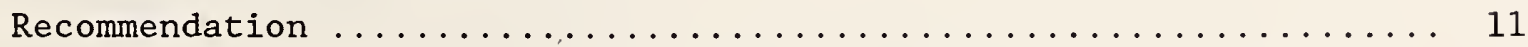

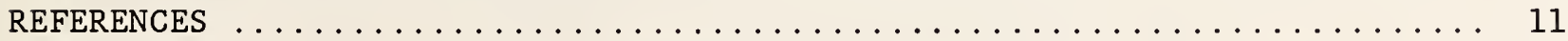

APPENDIX 1. FIRE PLUME FLOW THROUGH A HOLE IN THE TOP OF AN OTHERWISE

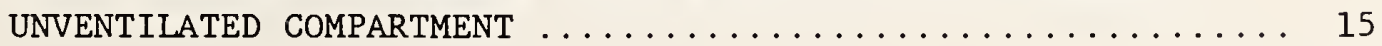

APPENDIX 2. FIRE PLUME IMPINGING ON THE CEILING OF A COMPARTMENT VENTILATED ONLY BY A HOLE IN THE CEILING DISTANT FROM

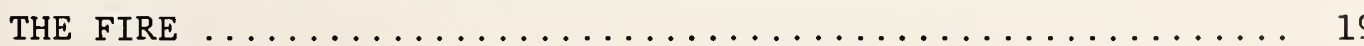

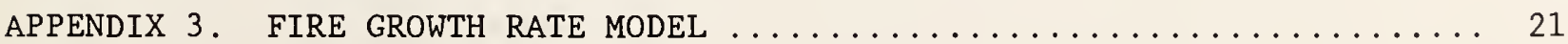




\section{LIST OF FIGURES}

Page

Figure 1. Fires ventilated from above: steady state model ........ 28

1a. Unconfined plume

1b. Plume flowing through a hole with simultaneous inflow

Figure 2. Fires ventilated from above: unsteady mode1 ...........

2a. Initial stages of outflow cycle

2b. Inflow cycle (or possible steady state)

Figure 3. Relation of fire development to fire control capability ..... 
b plume half width

C constant in eq 5

c specific heat

D equation subgroup in $\mathrm{A} 1.7$

f oxygen mass fraction

G $\mathrm{h} / \sqrt{ } \mathrm{k} \rho \mathrm{c} \beta$

h heat transfer coefficient

I integral

K kernel function

k thermal conductivity

m mass flow

$\mathrm{N}$ number, equation subgroup in $\mathrm{Al} .7$

$\mathrm{O}_{2}$ oxygen mass flow

$\mathrm{p}$ dummy variable

Q heat flux

q heat $f l u x$

$\mathrm{R} \quad \sqrt{\mathrm{R}^{2}+\mathrm{x}^{2}}$

$r$ fire radius

s dummy time variable

$T$ temperature

$t$ time, dummy variable

$\mathrm{u}$ temperature function

$\mathrm{V}$ flame spread velocity

$v \quad w_{i n} / w_{0}$, temperature function

$w$ vertical velocity

$\mathrm{x}$ (radial) distance from flame

\section{Greek letters}

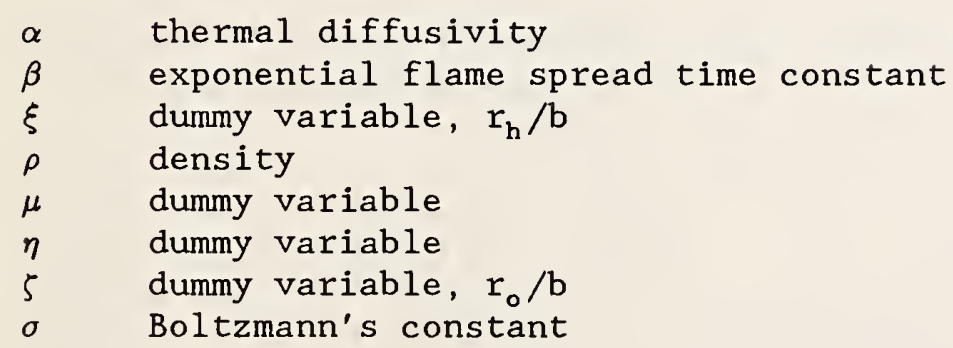

\section{Subscripts}

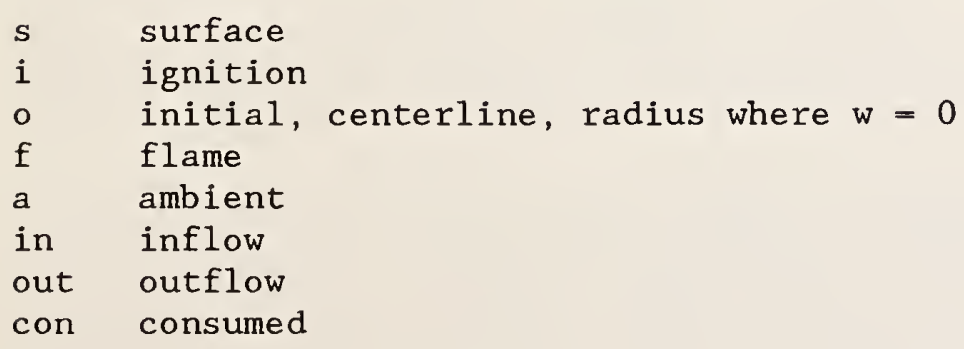




\section{Superscripts}

- per unit time

per unit area 
Fire Growth in Combat Ships

by

John A. Rockett

\section{ABSTRACT}

Several enrichments to FIRMOD, the Navy's ship battle damage estimation computer program, are considered. Some proposed enrichments could now be made to good effect, others should only be considered after further experimental work has been done to better define the phenomena involved and the algorithms to be used.

Enrichments recommended for immediate consideration are exponentially growing fires, ingestion by one ventilation system of smoke issuing from other ventilation system exhausts, and smoke transport between spaces served by the same ventilation system. Areas where further experimental work is recommended before FIRMOD enrichments are considered include fires ventilated primarily from above and buoyant smoke transport up shafts and ladderways.

\section{EXECUTIVE SUMMARY and RECOMMENDATIONS}

Three issues raised in an earlier study of fire in combat ships [1] are addressed: (1) Fires ventilated principally from above, (2) Prediction of fire growth rates, and (3) Spread of smoke and toxic gas.

In the case of the first, fires vented from above, model equations are developed for the steady burning case, the one to be expected where the fire is relatively small compared to air supply capability of the ventilating hole. The equations are a straight forward extension of conventional buoyant plume theory, but are intricate and involved. The unsteady case - larger fire and/or smaller hole - is very likely to occur and will present significantly more difficult firefighting problems. For this the situation is sufficiently complex and poorly understood that experiments should be undertaken before analytic work is attempted. (The experiments might also suggest a simpler model for the steady state case.) Experiments would identify the important elements of the problem allowing a sound, efficient model to be built. The main text of this report suggests that three elements of the experimental design will be important: the ratio of the ventilation opening area to the fire size, the area and heat transfer properties of the walls, floor and ceiling, and the mixing of incoming air and vaporized fuel within the room - i.e., the location of the fire relative to the ventilating hole.

The study of fire growth rates was undertaken because, although it would be desirable to include fire growth in FIREMOD, a way to get suitable input data is needed. The study establishes a cross walk between small scale test data and the needed model inputs. The model assumes that transient heating of the fuel ahead of the flame controls flame spread. It deals specifically with 
exponentially growing fires, and fire conditions likely to result in this type of growth are considered (some conditions which would cause deviations from this type of growth are also identified). Experiments are recommended to verify the fire growth formula developed and to define more precisely the relation between the exponential growth parameters and the data produced by the IMCO, or similar small scale test apparatus.

The ability to predict the spread of smoke and toxic and/or corrosive fire gases is very important to estimating ship survivability. One fairly simple improvement to FIREMOD is suggested: inclusion of the possible ingestion through the ship's forced ventilation system inlets of smoke exiting from exhaust vents of the ventilating system. Existing smoke movement algorithms, developed for use with building HVAC system analysis, could be added to FIREMOD. These would allow better estimates of the efficacy of fire dampers to be made and would give FIREMOD state of the art capability relative to the transport of smoke by the forced ventilating system. It is noted that the vertical, buoyant transport of gases in shafts and ladderways is not well understood and the horizontal transport in long corridors is only just beginning to be systematically studied. For these two important aspects of smoke transport additional experimental work is recommended as an adjunct to modeling efforts.

\section{INTRODUCTION}

This is a follow-on to the work of Quintiere, Baum and Lawson [1]. Three specific elements for possible enrichment of the fire growth model for use in combat ship damage control (FIREMOD [2]) have been studied. One element is the burning of a fire in a compartment whose only ventilation is via a relatively small hole in its upper surface. The second is the prediction of fire growth rates, and the third is the transport of smoke and toxic fire gases to non-fire involved parts of the ship.

\section{FIRES VENTILATED ONLY FROM ABOVE}

As pointed out in [1], many shipboard fires are likely to be ventilated primarily from above. The water-tightness of the ship's hull, if nothing else, leads to this. Such a fire can be expected to be "ventilation limited" at quite small fire sizes. To understand this, consider the simple, idealized case of a compartment whose only opening is a circular hole in its top, well away from any wall. Two cases will be considered, one which leads to steady burning, and a second which leads to non-steady, pulsating burning.

Steady state model

The steady state case arises when the fire is relatively small compared to the hole size. For this, suppose that a circular fire of known radius originates and grows on the floor of the compartment directly under the center of the hole. A plume of flame and hot gases will rise from the fire and try to exit via the hole. This plume will be turbulent and oscillating in size and 
strength. However, on the average, the highest velocity flow will occur along the fire centerline. The average velocity, temperature and combustion product concentrations will decrease exponentially with the square of the radial distance from the axis (Gausian distribution [3]). But, except for transient situations, gas cannot flow out the hole unless an equal mass of gas flows in and, since there is only one hole in the compartment, the outflow and inflow will compete for its use. Under quasi steady-state conditions, we can imagine that the actual flow through the hole is a superposition of the Gausian outflow and a uniform inflow (see figure 1). To have a mass balance, the inflow must adjust itself until the net outflow of the hot gases from the center of the plume is just balanced by the inflow of cool, ambient air around the plume's perimeter. As this ambient air enters it will entrain and carry back into the room the combustion products and enthalpy of the gas in the outer part of the fire plume. Thus, after entering, the incoming gas will no longer be "fresh air" but air contaminated with combustion products. For larger fires, with larger diameter plumes, pollution of the incoming air by recirculated combustion products will become more severe as a larger fraction of the plume outflow is entrained and returned to the room by the inflow. This model is developed in Appendix 1. It is to be expected that it will be valid for small fires aligned directly under a relatively large hole. Steady-state burning can be expected for this case provided the ventilation requirements of the fire are small compared to the hole's carrying capacity. A common example of a steady burning fire ventilated only from above is the candle in a "brandy sniffer" often found on restaurant tables.

Although fairly straight forward, the equations of this model are involved and non-linear, requiring iterative, numerical solution. In view of the dearth of experimental data on fires ventilated only from above, it is recommended that these ideas not be pursued further until some experimental verification is obtained. Initial tests of this model could be done with "fresh-water, salt-water" experiments. These would, of course, have to be followed by actual fire experiments to determine the qualitative behavior as the fire became ventilation limited. Small scale (room about $1 \mathrm{~m}$ height) fire tests should be used for the initial part of the fire test program with full scale tests only after a satisfactory analytic model had been assembled.

Transient mode1

An alternate, more complex model can be used to describe the above phenomena under transient conditions. The discussion is simplified if we consider that the fire is laterally well displaced from the hole in the ceiling. In this case, hot gas will be delivered by the fire plume to the vicinity of the ceiling at a rate depending, initially, on the fire to ceiling distance but only weakly on the heat release rate of the fire. The hot gas spreads under the ceiling and some of it, upon reaching the hole, will flow out. Hot gas outflow occurs because buoyancy has brought the hot gas to the hole, but, more importantly, gas is driven out because the fire releases energy within the room. Some of this energy is transferred to the surfaces of the room, but much of it remains in the fire gases. It is a consequence of the perfect gas law, which is a good approximation for fire situations, that the total energy of the gas in a vented room must remain constant. Thus, if energy is added to the gas in the room, there will be a transient pressure rise 
causing gas to be expelled until the rate of energy removal from the compartment (enthalpy flow of the expelled gas) balances the net rate of energy addition by the fire to the gas remaining in the room (rate of heat release less that lost to the room surfaces).

Fire plumes entrain a great deal more air between the fire base and the height of the visible flame tip than they need for stoichiometric burning [3]. If enough gas is delivered by the plume to the ceiling, not all of it will be driven out the hole; the excess accumulates below the ceiling as a growing hot layer. As this layer thickens, less flow will be delivered to it by the plume since the mass flow into the layer ultimately depends on the distance from the fire to the base of the hot layer. At some thickness of the layer it would no longer grow, provided a source of fresh air were available from below. However, no such source is presumed to be available. Therefore, as the initial charge of fresh air is consumed by the fire, the layer continues to sink. Ultimately the descending hot layer will submerge the burning surface in oxygen depleted fire gases. The result is a diminution of the burning rate which further decreases as the air becomes more severely depleted of oxygen. Since heat will still be lost to the room surfaces, at some point the fire will release less energy than is being lost by the hot layer gas to the room surfaces; the net rate of energy deposition in the gas will become negative and, just as heat addition caused gas to be expelled, heat removal will cause air to be drawn in, to keep the total energy of the room gas constant. The fresh air flowing in the ceiling hole, being cooler and denser than the gas in the room, will plunge through the hot layer (see figure 2). In doing so it entrains hot gas, forming an image to the fire plume - a falling plume with a dense, cold core, trailing off in a Gausian decay to the properties of the combustion products found in the hot layer. Thus the gas reaching the lower part of the room will no longer be pristine, cool, fresh air, but air contaminated with combustion products. Just as the hot gas from the fire plume formed a layer which spread under the ceiling, the plume of cool, descending air will form a cool layer spreading across the floor. This will eventually reach the fire base. Although partially vitiated by entrainment of hot layer gases, the oxygen of the air which entered the room will become available to the fire and the fire will increase in intensity. The total energy in the room will increase and a second puff of hot gas will be expelled from the hole, blocking inflow and setting the stage for another die-back due to oxygen starvation. The puffing frequency depends on the time it takes for the fire to become oxygen limited, the time it takes for the gases to cool down, the time for a fresh charge of air to enter, sink to the floor and spread to the fire base, and the time for the fire to form a new rising plume.

Note that, in this model, flow is either wholly in or wholly out the vent. Bi-directional flow through the ceiling hole does not occur. In reality, there will be periods of bi-directional flow around the time of flow reversal. Unfortunately there is no satisfactory model for such transient flow. The assumption of the present model is that the periods of bi-directional flow are short enough that they will have little effect on the total cycle. One purpose of an experimental program would be to ascertain if this assumption is viable. 
This model is discussed more quantitatively in Appendix 2, however, a complete, consistent set of equations have not been developed. The work of Porter [29] on the burning of alcohol fires ventilated only from above supports the qualitative features of this model. Scaling laws based on his analysis suggest that the "puffing" of fires, as postulated here, would be a maximum for holes in the rang of $1 / 2$ to $1 \mathrm{~m}$ in diameter for a typical ship compartment.

The complexity of this model and the uncertainties associated with the analysis suggest, as in the case of the steady state model, that experimental verification of the model should be sought before an effort is made to develop its equations and incorporate it in FIREMOD. This model cannot be tested with "fresh-water, salt-water" experiments as it depends on the thermally induced expansion of the gas and heat transfer to the compartment walls. Small scale fire tests should be used. To aid flow visualization, normal smoke production might be augmented with artificial aerosol. If a methane gas burner were used for the fire source, the aerosol could be added alternately to the fire gas, or the air entering, so that the two parts of the flow system could be observed. Again, small scale fire tests (room about $1 \mathrm{~m}$ high) should precede any full scale tests. The fire size should be large enough to guarantee turbulent plumes, but otherwise as small scale a test as possible would reduce costs and facilitate variations in the fire-room-hole geometry and changes in instrumentation. Once suitable instrumentation and data sampling locations had been determined and a viable model selected, larger scale tests could be contemplated for confirmation of the model and development of a data base for FIRMOD computations.

\section{PREDICTION OF FIRE GROWTH RATES}

Quintiere et al have laid the ground-work for this study in [1]. They point out (their Appendix B) that the heat release rate of many fires increases exponentially with time. In their main text, equation $9 b$, they present a case whose analysis leads to this result - fire spreading through a porous fuel bed as a result of radiant heating from the fire itself. This result is more general than the text suggests. It's generality depends primarily on the fact that the radiant flux, which heats the uninvolved fuel, is a simple function of the fire size. There are a number of other, important cases where this same type of behavior is found.

\section{Exponentially growing fires}

A number of workers have noted that fires grow exponentially with time. $[5,6,7]$. This is used in the Harvard/NBS fire models to calculate the rate of growth of fire radius and burning intensity, [5]. At present there is no available model for predicting the characteristic time for this growth. Thus, in the Harvard/NBS models, the fire growth rate is an input parameter derived from experimental data for the fuel type and geometry in question. Obviously some more general approach is desirable as it may not be feasible to obtain suitable experimental data for all fuels of importance. As stated above, thermal flame spread theory suggests an approach.

If heat is applied uniformly to the surface of a flat material (fuel) we need consider only one-dimensional heat conduction in calculating the 
material's surface temperature. If the heat is applied non-uniformly, but in such a way that temperature gradients along the surface are small compared to those normal to the surface, lateral heat conduction in the fuel will be small compared to that normal to its surface and a one-dimensional heat transfer model may still be adequate. For many cases this approach is, indeed, suitable. The principal exception is near extinction (very slow flame spread), where the flame spread rate is comparable to or less than the surface regression rate. Assume that extinction is not our present concern, and, therefore, the one-dimensional approach may be adopted. Let the thermal response of the fuel surface at $x$ to a unit heat pulse be $K(t)$. Then the surface temperature at this point as result of heating by a time varying heat flux $\dot{q}^{\prime \prime}(x, t)$ per unit area (incident at $x$ ) is

$$
T_{s}(x, t)-T_{0}=\int_{0}^{t} K(s) \dot{q}^{\prime \prime}(x, t-s) d s
$$

An expression for $K(s)$ is developed in Appendix 3. Note that setting $T_{s}=T_{1}$, the material's ignition temperature, in equation 1 results in an implicit equation for $t(x)$, the time necessary for the fuel at $x$ to be heated to ignition. The flame spread velocity is then related to the inverse of this, $x(t)$, by $V=d x / d t$. We defer discussion of the use of equation 1 and focus our attention next on $\dot{q}^{\prime \prime}(x, t)$.

Modak [8] shows that the radiation from a flame to an upward facing target in the plane of the fire base can be approximated as coming from a point source on the fire axis, one fire radius above its base.

$$
\dot{\mathrm{q}}^{\prime \prime}=\dot{\mathrm{Q}}_{\mathrm{f}} \cos (\theta) /\left(4 \pi \mathrm{R}^{2}\right)
$$

where

$\dot{\mathrm{Q}}_{f}$ is the radiated portion of the fire's energy release rate

$R$ is the distance from the virtual point source ( $r$ above the center of the fuel) to the point being heated, $\mathrm{R}=\sqrt{\mathrm{x}^{2}+\mathrm{r}^{2}}$

$\cos (\theta)$ is the radiation view factor $=r / R$

This approximation increases in accuracy as $r / R$ decreases, but is approximately true for all points outside the flame.

For a fire spreading across a horizontal surface, $\dot{Q}_{\mathfrak{f}}$ will be related directly to the average heat release rate of the flame per unit of fuel burning area.

$$
\dot{\mathrm{Q}}_{\mathrm{f}}=\dot{\mathrm{Q}}_{\mathrm{f}} " \pi \mathrm{r}^{2}
$$

deRis [9] cites data which indicate that, for fires above about 1 meter in diameter, $\dot{Q}_{f} "$ is independent of fire size for any given fuel. For smaller fires this is approximately true. Further, and consistent with this, for fires 
above about $1 \mathrm{~m}$ in diameter, flame radiation dominates the forward heat transfer process (convection may be neglected). Thus, $\dot{Q}_{f}$ does imply a length scale, but it is the fire radius.

From this we see that, for fires spreading on a horizontal surface, it is approximately true that

$$
\begin{aligned}
& \dot{q}^{\prime \prime}(x, t)=\dot{Q}_{f} \cos (\theta) /\left(4 \pi R^{2}\right)
\end{aligned}
$$

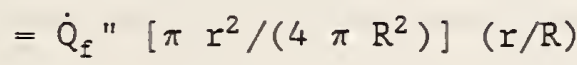

$$
\begin{aligned}
& =\dot{Q}_{f} " / 4(r / R)^{3}
\end{aligned}
$$

Note that, in this, $\dot{Q}_{f} "$ is a constant and $r=r(t)$. In Appendix 3 this expression, together with the $\mathrm{K}(\mathrm{s})$ developed there, is used to derive the flame spread velocity. The result is

$$
V=C[x /(k \rho c)]\left\{\left[\dot{Q}_{f}^{n} /\left(T_{i}-T_{0}\right)\right]-N * h\right\}^{2}
$$

where $\mathrm{x}=$ distance from the fire center to its edge

$\dot{Q}_{f}^{\prime \prime}=$ radiated portion of the flame's heat release rate per unit burning area

$\mathrm{T}_{\mathrm{i}}=$ material ignition temperature

$\mathrm{T}_{0}$ = material initial temperature

$h=$ convective plus linearized radiative surface heat transfer coefficient

$\mathrm{N}=\mathrm{a}$ numerical factor, approximately 20 (see Appendix)

$C=$ a numerical constant approximately $=1 / 247$

This is shown in the Appendix to be consistent with an exponential growth of fire radius with time.

How good is this formula? One question, assuming that the formula is adequate, is are we any better off with it than we were before? Although, with this formula, horizontal slabs of fuel may not have to be burned to determine the fire spread rate, it may not be easy to get data on the thermal inertia $\left(\mathrm{k} \rho \mathrm{c}\right.$ ) and ignition temperature, $\mathrm{T}_{i}$, so that the formula can be used. Thus a study of the burning rate results cited in $[5,6,7]$ yielded only enough data for two materials, out of a total of 15, to make comparisons with the formula. These two were qualitatively ranked by the formula (see below). Gross and Loftus [10] found good agreement for a similar formula applied to flame spread data from the ASTM E-162 flame spread apparatus. Their results applied only to the effect of $(k \rho c)$. Rockett [11] extended the thermal flame spread concept to a more complete analysis of the E-162 apparatus. He included the competing effects of convective cooling and radiative heating by the radiant panel and the approaching flame. The resultant analysis gave good results both in 
calculating the flame spread velocity and also in predicting other aspects of the E-162 test. Quintiere et al. [12] and Atreya et al. [33] have used similar concepts to correlate flame spread data from the proposed IMO apparatus (horizontal spread on a vertical surface). This suggests that the thermal spread concept is promising.

Calculated values for the exponential growth time constant, neglecting fuel surface re-radiation and convective heat loss, and using the $C$ value just refereed to, were $281 \mathrm{sec}$. for PMMA (compared to experimental values of 120 to $444 \mathrm{sec}$ ) and $7.95 \mathrm{sec}$. for urethane foam (compared with experimental values of 6.6 to $100 \mathrm{sec}$ ) Considering the approximations in the model and the scatter of the experimental data this is quite encouraging.

Gross [13] has collected thermal property data for a number of materials. His work shows that thermal properties of many materials of technical interest vary with temperature sufficiently that this variation should be taken into account when evaluating equations like 5. However, for a use such as FIREMOD, where many other, severe approximations must, of necessity, be made, it is not clear that the additional accuracy would justify the added complication of temperature dependent material properties.

With exponential fire growth models, there is always the question of what initial fire size to pick. A decrease of an order of magnitude in initial fire area results in an increase of about 1.5 characteristic times for the fire to reach a given size ${ }^{1}$. If the characteristic time for fire growth is short compared to the time for other critical events, such as damage control crew response, then initial size is not particularly important. Flashover will probably have occurred, if it is going to, before intervention is possible, whether the number of characteristic times is increased by one or two or not.

The exponential growth model could, in general, be used as follows: The response time and fire control capability of the damage control parties must be known. Control capability should be expressed in terms consistent with the fire growth model, i.e., energy release rate, fire area (or radius), etc. (as functions of time) for which control is possible. At least two levels of control may be specified: the ability to extinguish and the (lesser) ability to prevent extension beyond some defined fire barrier. The initial fire size, estimated by methods to be discussed below, and characteristic fire growth time are computed. Then FIRMOD looks to see if, after the response delay, the fire control capability exceeds the fire challenge for a sufficient time to allow extinguishment, see figure 3. If the answer were that control capability did exceed fire challenge then control would be assumed, if not, uncontrolled growth to the limit size (ventilation or fuel area limit) would be assumed. With weaker control capability alternative "end points" would, of course, apply.

When fire growth time and other times are comparable, the ability to estimate initial fire size is important. Obviously this is highly incident

${ }^{1}$ The characteristic time is $1 / \beta$ where $\beta$ is given by $A 3.3$ 
dependent, no general rule for estimating initial fire size can be given. In the next paragraphs a few guide-lines are suggested.

If the fire is due to a flammable liquid spill, fire size, for most liquids, will grow very rapidly to cover the entire spill area, after that, fire area will most likely depend on the rate of supply of additional liquid and physical bounds to the liquid's spread. The fire will not grow exponentially. Burning intensity can be calculated using an algorithm similar to that used in Harvard $V$ for pool fires. The fire area would be considered quasi-static at the current spill area.

If there is no liquid spill, and the impacting object is not itself the initial fire, assume, first, that the fuel present in the space has been effectively homogenized by the initial damage and that multiple fires are started by impact of high kinetic energy fragments. At this point a decision must be made whether to assume exponential growth as given by the present model, equation A3.3, or some other model such as [1], equation 9. Assuming that the present model fits the supposed circumstances, assume that each of these fires grows independently with the same characteristic time. (Because each ignition in the space is considered to involve the same homogenized fuel.) If there were $n$ fragments, causing $n$ equal, initial fires of radius $r_{0}$, then, after these have grown and merged to form a single fire, the equivalent initial single fire radius would have been $r_{i}=\sqrt{n} r_{0}$. Thus, if $n=100$ and $r_{0}$ is $2 \mathrm{~cm}$, the equivalent initial fire, after complete merging of the separate fires, would have had a radius of $20 \mathrm{~cm}$. A suitable guess for the initial fire size for the separate fires would be the fragment size. More complex expressions can be written for a distribution of initial fire sizes and non-uniform fire spacing, but the added accuracy is probably not justified due to the uncertainty in modeling the initial event.

Where the initial fire is the impacting object, the size of the object itself can be assumed to be the fire size. Growth may or may not be exponential. An expert on the particular device should be consulted for an estimate.

\section{SPREAD OF SMOKE AND TOXIC GAS}

The ability to predict the spread of smoke and toxic gas associated with a fire has become a significant issue. The following is a discussion of improvements which might be considered for the FIRE DAMAGE SIMULATION MODEL (FIRMOD).

Two mechanisms of smoke transport are important - smoke entering the ship's ventilating system and being carried by the system to non-fire involved spaces, and smoke transported, by natural convection generated by the fire, through openings of the fire compartment into adjacent spaces and thence to more distant locations.

Fire gases can enter the ventilating system by two routes: fire gases exiting through holes in the deck or ventilation system exhausts may pass near ventilation inlets and be drawn into these adjacent systems, or they can directly enter the ventilation system of the fire involved space. Where this 
ventilation system serves several spaces, there is the likelihood that the fire gases will be carried by the system to these. An unpublished review of the ventilation system of one frigate [30] suggests that both mechanisms may be important. FIRMOD already accounts for the first mechanism where the hole is weapons caused, but the frigate's ventilation system showed numerous cases where the exhaust from one space was located near enough the intake for another that, even without battle damage caused smoke vents, ingestion could be a problem. Where ventilation systems are not provided with fire dampers, gases from a fire in one space would be exhausted by its ventilation system and could be ingested by a neighboring system. To include smoke ingestion, the relative locations of the various vent system exhausts and inlets must be considered as well as the ship's heading and speed relative to the wind. FIREMOD already has provision for the effects of heading and speed, so the only new element would be recording the relative locations of ventilation system exhausts and calculating the smoke discharge from the exhaust vents. The present calculation, or an improved version of it, could then treat a smoke emitting exhaust just as it now treats a smoke emitting battle damage caused hole with respect to ingestion of smoke by other systems.

On this same frigate a number of ventilation systems served multiple spaces. Fire in one space could result in fire gases reaching other compartments on the same system. This would be especially true if a high recirculation ratio were used with the ventilation system and fire dampers were not provided in the system's ducts. Present computer models for smoke control $[14,15]$ assume that the ventilation system air flows are known and unaffected by the fire, except where automatic fire dampers are provided. Thus the computation of smoke transport via the ventilation system is a matter of identifying the "nodes and flows" of the system. Smoke transport would be considered as "slug flow" ingested by the exhaust from the fire room, diluted by mixing at the nodes, and supplied to other spaces as the system design dictates.

Fire induced natural convection is often the most important mechanism for smoke migration from the fire to other areas. This is not currently modeled in any detail by FIREMOD. Modeling of buoyancy induced flows on a single level has been well developed in the past decade $[16,17]$. However, recent studies $[31,32]$ suggest that present, widely used two zone models may not be appropiate for long corridors. Computer fire models have been published recently which treat multi-level structures $[18,19]$. They model well the (Japanese) vertical transport data available at the modelers own laboratory. However, the algorithms used in these multi-level programs may not correctly account for interference between the rising and expanding gas plume and the walls of the vertical channel. Other experimental data relating to buoyant flow in vertical shafts is the work of Cannon and Zukoski [20]. Their work is based on "salt water analogue" experiments which, though qualitatively correct and semi-quantitative, may not give sufficiently accurate results for correct modeling. It suggests interference effects not included in the Japanese model. The techniques used in $[16,17]$ are probably as detailed as can presently be justified for smoke transport on the level of the fire. The techniques of $[18,19]$ are open to question but are as good as currently available knowledge. Their predictions should not be considered always quantitatively accurate and might, occasionally, be qualitative misleading without further analysis. 
Recommendation

As indicated above, a relatively minor modification to FIRMOD would account for the possible ingestion of smoke disgorged by ventilation system exhausts from burning spaces. This would seem to require relatively minor program changes and could be a significant improvement. A more extensive change would be inclusion of the transport of smoke by the (undamaged) ventilation system from a fire involved space to other spaces served by the same system. This would only be a significant improvement if the ship's ventilation system were without fire dampers (apparently rarely used on present ships) and if relatively high recirculation ratios were used (less common). The computing techniques for analysis of forced ventilation systems are well established. The value of these additions would, as indicated, depend to some extent on the design of present fleet ventilation systems. Buoyancy driven smoke transport as treated by present "two layer" room fire models is a more ambitious addition to FIRMOD as it requires all the computational features needed to track the energy and mass content of the two layers. However, various levels of modeling detail can be adopted with corresponding levels of numerical complexity. Thus ASET [27] is very much simpler than NBS/Harvard VI [16] or FAST [17] but captures some essential features of the two layer model. For vertical transport the Japanese modeling technique [18,19] could be used, but the methodology for buoyant transport up shafts and ladderways is not as well developed as horizontal transport. Vertical buoyant transport is likely to be at least as important, if not more important than buoyant transport on the same level as the fire. Therefore, it seems advisable to begin an experimental and analytical program to document and understand the various regimes of vertical transport, the conditions under which they occur and how they should be modeled. Concurrent with the experimental program the feasibility of including a two layer buoyant gas model for the level on which the fire occurs could be explored. If this were added to FIRMOD it would complement the inclusion of exponentially growing fires, but the exponentially growing fire addition does not, of itself, require the two layer model (see discussion above).

\section{REFERENCES}

[1] Quintiere, J.G., Baum, H.R. and Lawson, J.R., "Fire Growth in Combat Ships", NBSIR 85-3159, U.S. National Bureau of Standards, Gaithersburg, MD 20899, May 1985

[2] Tinker, C.W. and Hackett, O.F., "FIREMOD user's guide", TN 174-49, David W. Taylor Naval Ship Research and Development Center, 1985 (Distribution: "For Official Use Only")

[3] McCaffrey, B.J., "Purely Buoyant Diffusion Flames: Some Experimental Results", NBSIR 79-1910, U.S. National bureau of Standards, Gaithersburg, MD, 20899, (1979)

[4] Rockett, J.A., "Fire Induced Gas Flow in an Enclosure", Combustion Science and Technology, 1976, Vol 12, pp 165-175 
[5] Mitler, H.E., "The physical basis for the Harvard computer fire code", Home fire project technical report No. 34, Harvard University, Cambridge, MA (Oct. 1978)

[6] Pape, R., Mavec, J., Kalkbrenner, D. and Waterman, T., "Program documentation and users guide, Semistochastic approach to predicting the development of a fire in a room from ignition to flashover, RFIRES", Engineering Mechanics Division, Ill. Inst. of Tech., 10 West 35th St., Chicago, I11 60616 (June 1976)

[7] Huggett, C., "Time-dependent fire behavior of aircraft cabin materials", U.S. Dept. of Transportation, Federal Aviation Adm., Systems Research \& Development Service, Washington DC 20590 (Dec. 1977)

[8] Modak, A.T., "Thermal radiation form pool fires", Combustion and Flame $29,177-192$ (1977)

[9] deRis, J., "Fire radiation - a review", Factory Mutual Research Corp. Norwood MA, 02062 (Dec. 1978)

[10] Gross, D. and Loftus, J., "Surface flame propagation in cellulosic materials exposed to thermal radiation", Journal or Research, 67C, no 3 (July-(september 1963) pp 251-258, U.S. Nat. Bur. of Stds., Washington, $\mathrm{DC}$.

[11] Rockett, J.A., "Mathematical modeling of radiant panel test methods", Fire Safety Research, Proceedings of a symposium held at NBS, Gaithersburg, MD, August 22, 1973, pp 909-96, U.S. Nat. Bur. of Stds., special publication 411 (Nov.1974)

[12] Quintiere, J., Harkleroad, M., and Walton, D., "Measurements of material flame spread properties", Combustion Science and Technology, 1983, Vo1 32 , pp 67-89, 29, 177-192 (1977)

[13] Gross, D., "Data sources for parameters used in predictive modeling of fire growth and smoke spread", U.S. Nat. Bur. of Stds., (to be published)

[14] Klote, J.H., "Computer modeling for smoke control design", Fire Safety Journal, 9 (1985) 181-188

[15] Klote, J.H., "Smoke movement and smoke control on merchant ships", NBSIR 81-2433, U.S. Nat. Bur. of Stds., Gaithersburgh, MD December 1981

[16] Gahm, J.B., "Computer fire code VI - Volume 1", NBS-GCR 83-451, U.S. Nat. Bur. of Stds., Gaithersburgh, MD (December 1983).

[17] Jones, W.W., "A multicompartment model for the spread of fire, smoke and toxic gases", Fire Safety Journal, 9 (1985) 55-79.

[18] Tanaka, T., "A model of fire spread in small scale buildings", Building Research Institute (Japan), Research paper \#79 (1978) and \#84 (1980). 
[19] Tanaka, T., "A model of multiroom fire spread", NBSIR 83-2718, U.S. Nat. Bur. of Stds, Gaithersburh, MD, (August 1983).

[20] Cannon, J.B. and Zukoski, E.E., "Turbulent mixing in vertical shafts under conditions applicable to fires in high rise buildings", Daniel and Florence Guggenheim Jet Propulsion Center, Calif. Inst. of Tech., Pasadena, CA, Technical Report No. 1, National Science Foundation Grant No. GI $31892 \mathrm{X}$, (January 1976).

[21] McCaffrey, B.J., "Momentum implications for buoyant diffusion flames", Combustion and Flame 52: 149-167 (1983)

[22] Morton, B.R., Taylor, G.I. and Turner, J.S., "Turbulent gravitational convection from maintained and instantaneous sources", Proc. of the Royal Soc., London, A, 234,1-23 (1956)

[23] Turner, J.S., "Buoyancy effects in fluids", Cambridge University Press, 1973

[24] Torrance, K.E., Orloff, L. and Rockett, J.A., "Experiments on natural convection in enclosures with localized heating from below", J. Fluid Mech. (1969), vol 36, part 1, pp 21-31

[25] Torrance, K.E. and Rockett, J.A., "Numerical study of natural convection in an enclosure with localized heating from below - creeping flow to the onset of laminar instability", J. Fluid Mech., (1969), vol 36, part 1, pp $33-54$

[26] Alpert, R.L., "Fire induced turbulent ceiling-jet", FMRC Technical Report 19722-2, Factory Mutual Research Corp. (1971)

[27] Cooper, L.Y. and Stroup, D.W., "Calculating available safe egress time (ASET) - A computer program and user's guide", NBSIR 82-2578, U.S. National Bureau of Standards, Washington, D.C. 20234, Sept. 1982

[28] Carslaw, H.S. and Jaeger, J.C., "Conduction of heat in solids", Second Edition, Oxford, 1959

[29] Porter, J.W., "Pulsating Combustion of Liquid Fuel in Partially Closed Vessels", Combustion and Flame, Vol 11, No 6, Dec 1967

[30] Jones, W.E., private communication

[31] Zukoski. E.E., Kubota, T., and Lin, C.S., "Experimental study of environment and heat transfer in a room fire. Mixing in doorway flows and entrainment in fire plumes", NBS-GCR-85-493, U.S. Nat. Bur. of Stds, Gaithersburg, MD 20899, May 1985

[32] Baum, H., Seminar lecture at the NBS Center for Fire Research, 1986 and Private communication 
[33] Atreya, A., Carpentier, C., and Harkleroad, M., "Effect of sample orientation on piloted ignition and flame spread", NBS-IR (in preparation, 1986), U.S. Nat. Bur. of Stds., Gaithersburg, MD

[34] Quintiere, J.G., private communication and unedited video tape (copy) brought from Japan

[35] Takeda, H., "Experimental Investigation of PMMA Compartment Fire", Fire Science and Technology, Vol. 5, No. 1 (1985) pp. 11-20. 
The strategy of this appendix is as follows: The "standard, point source buoyant plume solution" [22] is used to compute the upward flow of mass and oxygen as a function of radius and height. Next, similar calculations for a point plume, but with a different half width, and with a superimposed, uniform downward velocity are carried out. Third, the inflow through the ceiling hole, in the presence of the retarded plume outflow, is found. Fourth, the mass inflow and outflow are equated. This yields the value for the inflow velocity and, from the plume equations, the dimensionless radius of the zero velocity location. Fifth, the mass and oxygen flow in the core of the "free plume" of the first calculation is equated to the corresponding flows in the retarded plume. This determines the dimensionless radii in the two plumes where the flows are equal, which, using the already determined dimensionless radius of the zero velocity point, fixes the radius of the free plume core. The second set of equalities is used to set the ratio of the plume half widths. It is presumed that the free plume half width is known from the burning conditions and the plume heat release rate. Note that, in this, it is necessary to choose an upward velocity on the plume axis for both plumes. It is assumed that this is the same for both and that of the free plume will be known. Finally, the outer mass and oxygen transport of the free plume is found. This is the recirculating mass and oxygen. Using this and the mass and oxygen inflow, the oxygen mass fraction in the room can be found. This allows the burning conditions for the free plume to be found. The oxygen consumption is the difference between the oxygen inflow and outflow. This should be consistent with the plume burning conditions within the room, but does not necessarily represent the total heat released since additional heat may be released above the hole (i.e. in a flame extending through the hole).

In the absence of any obstruction to the fire plume's upward flow, the mass flow, several fire diameters above a pool fire, inside a radius, $r$, is given by

$$
\dot{\mathrm{m}}=\rho_{0} \mathrm{w}_{0} \int_{0}^{\mathrm{r}}\left[1-\frac{\Delta \mathrm{T}}{\mathrm{T}} \mathrm{e}^{-(\mathrm{r} / \mathrm{b})^{2}}\right] \mathrm{e}^{-(\mathrm{r} / \mathrm{b})^{2}} 2 \pi \mathrm{rdr}
$$

Here it has been assumed that the temperature excess and upward axial velocity are both Gausian distributed with a half width $b$.

$$
w=w_{0} e^{-(r / b)^{2}}
$$

and

$$
\begin{aligned}
\rho & =\rho_{0}\left[1-\frac{\Delta \rho}{\rho_{0}} e^{-(r / b)^{2}}\right] \\
& =\rho_{0}\left[1-\frac{\Delta T}{T} e^{-(r / b)^{2}}\right]
\end{aligned}
$$


The gas density far from the plume axis is $\rho_{0}$, the centerline velocity is $W_{\circ}$ and the centerline temperature excess is $\Delta T=\left(T-T_{0}\right)$. The gas temperature far from the plume axis is $T_{0}$. Similarly, the vertical mass transport of oxygen is given by

$$
\dot{\mathrm{m}}=\rho_{0} \mathrm{w}_{0} \int_{0}^{\mathrm{r}}\left[1-\frac{\Delta \mathrm{T}}{\mathrm{T}} \mathrm{e}^{-(\mathrm{r} / \mathrm{b})^{2}}\right] \mathrm{e}^{-(\mathrm{r} / \mathrm{b})^{2}}\left[1-\frac{\Delta \mathrm{f}}{\mathrm{f}_{\mathrm{o}}} \mathrm{e}^{-(\mathrm{r} / \mathrm{b})^{2}}\right] 2 \pi \mathrm{rdr} \quad(\mathrm{Al} .2)
$$

We now superimpose a uniform downward velocity, $W_{i n}$, on this upward flow. The down flowing gas has a density $\rho_{a}$. If the hole radius is $r_{h}$ and $r_{0}$ is the radius at which the superimposed down flow velocity equals the free plume upward velocity (i.e., the radius where the vertical velocity changes sign)

$$
w_{\text {in }}=w_{0} e^{-\left(r_{0} / b\right)^{2}}
$$

Then the net mass flow will be

$$
\begin{aligned}
& \dot{\mathrm{m}}=\dot{\mathrm{m}}_{\text {out }}-\dot{\mathrm{m}}_{\text {in }}=\rho_{\mathrm{o}} \mathrm{w}_{\mathrm{o}} \pi \mathrm{b}^{2} \int_{0}^{(\mathrm{r} / \mathrm{b})^{2}}\left(\mathrm{e}^{-t}-\mathrm{v}\right)\left(1-\frac{\Delta \mathrm{T}}{\mathrm{T}} \mathrm{e}^{-t}\right) \mathrm{dt} \\
& -\rho_{a b_{0}} \pi b^{2} \int_{\left(r_{0} / b\right)^{2}}^{\left(r_{h} / b\right)^{2}}\left(v-e^{-t}\right) d t
\end{aligned}
$$

For steady state conditions this must be zero, giving an implicit expression for $v=w_{1 n} / w_{0}$.

$$
\begin{aligned}
\rho_{\mathrm{a}}\left\{\mathrm { v } \left[\left(\mathrm{r}_{\mathrm{b}} / \mathrm{b}\right)^{2}\right.\right. & \left.\left.-\left(\mathrm{r}_{\mathrm{o}} / \mathrm{b}\right)^{2}\right]-\left[\mathrm{v}-\mathrm{e}^{-\left(\mathrm{r}_{\mathrm{o}} / \mathrm{b}\right)^{2}}\right]\right\}- \\
& \rho_{\mathrm{o}}\left[-\mathrm{v}\left(\mathrm{r}_{\mathrm{o}} / \mathrm{b}\right)^{2}+(1-\mathrm{v})-\frac{\Delta \mathrm{T}}{2 \mathrm{~T}}(1-\mathrm{v})^{2}\right]
\end{aligned}
$$

which, with Al.2, implies values for both $w_{i n}$ and $r_{0}$. The equations, being transcendental, can only be solved iteratively. Similarly, the steady state oxygen consumption will be the difference between the oxygen entering and that leaving.

$$
\begin{aligned}
\dot{o}_{2 \text { on }}= & \dot{o}_{2 \text { in }}-\dot{o}_{2 \text { out }}= \\
& w_{o} \pi b^{2}\left(\rho_{\mathrm{a}}\left(f_{a}-f_{o}\right)\left[v(5-\xi)-\left(v-e^{-\xi}\right)\right]\right. \\
& \left.+\rho_{o} f_{0} \frac{\Delta f}{f}\left[\frac{1}{2}(1-v)^{2}-\frac{1}{6}\left(2-3 v+v^{3}\right) \frac{\Delta T}{T}\right]\right)
\end{aligned}
$$


where $\mathrm{f}_{\mathrm{a}}=$ the volume fraction of $\mathrm{O}_{2}$ in the ambient air

$f_{0}=$ the volume fraction of $\mathrm{O}_{2}$ in the air in the enclosure

$\xi=r_{\mathrm{h}} / \mathrm{b}$ dimensionless hole radius

$\zeta=r_{0} / b$ dimensionless radius at which vertical velocity $=0$

The fractional amount of oxygen in the gas available within the room, at steady state, is the ratio of the oxygen entering plus the oxygen recirculated from the plume's outer sheath to the mass entering plus the mass recirculated.

$$
\mathrm{f}_{\mathrm{o}} / \mathrm{f}_{\mathrm{a}}=1 /\left\{1+\frac{\mathrm{D}_{2}}{\mathrm{D}_{1}}-\frac{\rho_{\mathrm{o}}}{\rho_{\mathrm{a}}} \frac{\mathrm{N}_{2}}{\mathrm{~N}_{1}}\right\}
$$

where

$$
\begin{aligned}
& \mathrm{N}_{1}=(\xi-\zeta)-\left(\mathrm{v}-\mathrm{e}^{-\xi}\right) \\
& \mathrm{D}_{2}=\frac{\rho_{\mathrm{o}}}{\rho_{2}}\left(\mathrm{v}-\frac{1}{2} \frac{\Delta \mathrm{T}}{\mathrm{T}} \mathrm{v}^{2}\right) \\
& \mathrm{N}_{2}=\mathrm{v}-\frac{1}{2}\left(\frac{\Delta \mathrm{T}}{\mathrm{T}}+\frac{\Delta \mathrm{f}}{\mathrm{f}}\right) \mathrm{v}^{2}+\frac{1}{3} \frac{\Delta \mathrm{T}}{\mathrm{T}} \frac{\Delta \mathrm{f}}{\mathrm{f}} \mathrm{v}^{3}
\end{aligned}
$$

Here $m_{i n}$ and $\mathrm{O}_{2 \text { in }}$ are as given above and $m_{r e c}$ and $\mathrm{O}_{2 \mathrm{rec}}$ are calculated from equation $A 1.1$ and $A 1.2$ integrated from $r$ to infinity.

A refinement to this model has been considered which adjusts the plume characteristics at the height of the hole for the deceleration caused by the inflow. Note, however, that this correction would only be significant where the inflow velocity was a major fraction of the free plume centerline velocity, $w_{\circ}$. In this case there would be high shear stress on the plume caused by the inflow. It is questionable if the present model would be valid were this the case. Thus the added complication does not seem justified.

The analysis presented here is incomplete in the sense that it does not include equations for the calculation of the characteristic plume width, b, or upward velocity, $w_{0}$. These calculations, however, follow directly from published work. For $b$ and $w_{0}$ there is the work of McCaffrey [3,21]. To use his results the heat release of the fire is needed. This is related to the oxygen consumption per equation Al.6 (using Al.7 to get $f_{o}$ ). Since all these equations are highly non-linear, an iterative solution scheme would be needed. Thus some management decision is needed relative to the amount of additional calculation permitted versus the added flexibility of the more complex model achieves.

\section{Critique}

The Gausian decay of plume properties is not the only way to interpret experimental plume data. If the plume properties show a "square hat" distribution, but the plume axis wanders with a Gausian probability, very 
similar data would be observed. For a "square hat" distribution, the above equations are slightly altered. The most significant difference is that, since there is no "tail" to the distribution, there is no vitiation of the incoming air. Since vitiation is expected, shear induced mixing has to be invoked in the locally high shear region around the vertical position of the hole. No model for this type of mixing has been proposed. In view of the total lack of experimental data for fires ventilated solely from above, it is recommended that, before this analysis is perused further, the ideas advanced be tested by experiment. They may then be accepted, altered, or rejected. To proceed without an experimental base seems unwise to the author. 
APPENDIX 2: FIRE PLUME IMPINGING ON THE CEILING OF A COMPARTMENT VENTILATED ONLY BY A HOLE IN THE CEILING DISTANT FROM THE FIRE.

The model assumes a single gas layer in the room. It is partially vitiated by the admixture of combustion products and warmed by these combustion products, but its primary characteristic is that its oxygen content is at the limiting value for combustion of the fuel in question and for a gas at the current temperature in the room. There are alternately two plumes in the room. A hot gas plume rising from the fire to the ceiling, when present, spreads under the ceiling and some gas flows out of the room via the hole. For simplicity assume the fire is flush with the floor of the room. The other plume appears as the fire dies down. It is formed of cold gas which descends from the ceiling hole through the warm gas layer to the floor. At the floor the cool plume gasses spread and some is entrained by the fire supplying fresh oxygen for combustion. Thus the fire is rejuvenated and the accompanying pressure build-up cuts off the descending plume as the ascending fire plume becomes re-established.

Turner tells us that the head of a buoyant plume advances at $61 \%$ of the plume velocity which would be found at that height after the plume has become established [23]. Experiments and numerical calculations by Torrance, Orloff and Rockett $[24,25]$ show that the head of the starting plume is a ring vortex. The vortex advances into essentially stagnant fluid, behind it the steady-state plume flow is fully developed. When the progress of the vortex is blocked by a ceiling (for a rising plume) or a floor (for a falling plume) it grows in diameter but still the ceiling jet behind the vortex is the fully developed flow and the fluid ahead of it is stagnant. Alpert [26] has studied the ceiling jet. Recent work [27-29] has focused on flow in corridors. Together these papers give a means of calculating the thickness of the ceiling (floor) jet; typically it will be about $20 \mathrm{~cm}$. What concerns us is that the ceiling jet has a definite, calculable thickness and volume and that the flow behind the front is essentially steady state (for a constant strength plume source). Using the plume relations of McCaffrey [21], we see that a jet of undiluted air $20 \mathrm{~cm}$ thick could supply enough air to the base of a fire for stoichiometric burning of about $41 / 2$ megawatts. Thus, even allowing that the descending plume will be vitiated by entrainment of room air, contaminated with combustion products, a very substantial fire can develope feeding on the floor jet created by the descending, fresh air plume.

The question may be raised, can this lead to steady-state burning rather than the cyclic condition described here and in the main text. If the carrying capacity of the hole is large compared to the needs of the fire, a steady-state solution certainly exists. The limiting situation will be related to the amount of shear which develops between the incoming and outgoing flows at the hole. Recall that, for steady state, just as in the case of Appendix 1 , the inflow and outflow must balance. At present, fluid dynamics cannot predict the conditions which will allow steady-state, nor the flow at the hole which will result. We can be reasonably sure, however, that for a small hole and a fire that is able to rebuild quickly, for example a flammable liquid spill, a pulsating fire should be expected. The exact conditions would have to be determined by experiment. 
Some times can be estimated. The plume velocity can be obtained from McCaffrey [3] as a function of fire size. For a $100 \mathrm{kw}$ fire the peak velocity would be about $5 \mathrm{~m} / \mathrm{s}$. Thus, from Turner [23], the head of the plume would travel at $3 \mathrm{~m} / \mathrm{s}$. It would take about a second for the fire plume to traverse a typical 2.5 to $3 \mathrm{~m}$ room height. The descending plume would be somewhat slower. It would take about two additional seconds to build a ceiling layer out to a radius of 2 meters. Thus the plumes can form in about 3 seconds (perhaps 5 for the descending plume). After the floor jet formed, the fire would continue to build even after the heat release had so built the pressure in the room that the entry of further fresh air had been cut off. The volume of fresh air available to feed the fire would depend on the room dimensions, the location of the fire relative to the hole, and the fire's build-up dynamics. Nevertheless, the longest time interval for this model seems to be either this, the time to use the fresh air charge, or the cool down time discussed next. The cycle time would also depend on the time for the walls to extract heat from the fire gas left when the fire died back. Porter [29] provided an expression only for this part of the pulsating burning cycle but got good agreement with the pertinent part of his experimential data. This too will depend on the room dimensions and also the thermal properties of the wall lining materials. If the walls are unprotected steel, heat will be absorbed as fast as it can be transferred to the walls. Even so, the heat transfer time can be comparable to the air burnout time. Time for a complete cycle is obviously a complex set of events, quite case dependent. It is estimated to be in the order of 20-30 seconds for a room about $3 \mathrm{~m}$ high and 4-5 meters in each lateral dimension. Experimental experience $^{2}$ could change this estimate by a considerable amount, though probably not an order of magnitude.

${ }^{2}$ Japanese experiments with a room lined with plywood covered by a thin layer of steel and ventilated by a door, developed pulsating burning. This may be related to a somewhat different set of circumstances within the room but the pulsation frequency was higher than our estimate for the fire vented from above. They observed about one pulse every one to two seconds. Successive pulses had a growing severity. The fifth or sixth pulse was a violent backdraft sending a large fire ball some distance out the door. The backdraft was followed by a short quiescent period and then another succession of gradually increasing pulses. $[34,35]$ 
APPENDIX 3: FIRE GROWTH RATE MODEL

This appendix has three parts. In the first, the kernel function, $K(s)$, of equation 1 is developed. In the second, this kernel is combined with the fire flux expression, equation 4 , and the resulting version of equation 1 studied. The assumption is made that the fire growth is exponential in time. This is shown to be consistent with the expanded equation 1 and the exponential growth parameter, $\beta$, is obtained. In the third part, several variations on the heat flux model are discussed and an expression for the fire spread velocity is generated by further approximations. The result is equation 5 of the main text.

Section A3.1: Development of $\mathrm{K}(\mathrm{s})$

The kernel function desired is the one-dimensional response of a semi-infinite solid to a (unit) radiant heat flux (per unit area) imposed at the surface of the solid $(z=0)$. The surface re-radiates to an ambient at temperature To and is convectively cooled by the flow, toward the fire, of gas at ambient temperature. The formulation follows [28] chapter 2. Thus we want a solution of

$$
\partial \mathrm{T} / \partial t=\alpha \partial^{2} \mathrm{~T} / \partial \mathrm{z}^{2}
$$

subject to the boundary conditions

$$
\begin{aligned}
& \mathrm{T}=\mathrm{T}_{\mathrm{o}} \text { for } \mathrm{t}=0 \text { and all } \mathrm{z}>0 \\
& -\mathrm{k} \partial \mathrm{T} / \partial \mathrm{z}=\dot{\mathrm{q}} "-\mathrm{h}\left(\mathrm{T}-\mathrm{T}_{\mathrm{o}}\right) \text { for } \mathrm{x}=0 \text { and all } \mathrm{t}>0
\end{aligned}
$$

where

$$
\begin{aligned}
& \mathrm{T}=\text { Temperature of the solid (above ambient) } \\
& \mathrm{T}_{0}=\text { ambient temperature, } \mathrm{T}_{0}=0 \text { assumed } \\
& z=\text { coordinate normal to the fuel surface } \\
& t=\text { time } \\
& \alpha=\text { the material thermal diffusivity, } \mathrm{k} / \rho \mathrm{c} \\
& \mathrm{k} \text { = the material thermal conductivity, assumed a constant } \\
& \rho=\text { material density, assumed constant } \\
& \text { c = material specific heat, assumed constant } \\
& \mathrm{h} \text { = linearized radiative plus convective heat transfer } \\
& \mathrm{h}=\mathrm{h}_{\mathrm{c}}+\epsilon \sigma\left[\left(\mathrm{T}_{\mathrm{s}}+\mathrm{T}_{\mathrm{a}}\right)^{4}-\left(\mathrm{T}_{\mathrm{o}}+\mathrm{T}_{\mathrm{a}}\right)^{4}\right] /\left[\left(\mathrm{T}_{\mathrm{s}}+\mathrm{T}_{\mathrm{a}}\right)-\left(\mathrm{T}_{\mathrm{o}}+\mathrm{T}_{\mathrm{a}}\right)\right) \\
& h_{c}=\text { convective heat transfer coefficient }
\end{aligned}
$$


$\mathrm{T}_{\mathrm{a}}=$ ambient temperature in Kelvin

$\mathrm{T}_{\mathrm{s}}=$ temperature of the material surface.

$\epsilon=$ material surface emissivity

$\sigma=$ Boltzman's constant, $\sigma=5.67 * 10^{-11} \mathrm{Kw} / \mathrm{m}^{2}-\mathrm{K}^{4}$

$\dot{q}^{\prime \prime}=$ radiative heat flux per unit area applied to the surface.

$\dot{\mathrm{q}}^{\prime \prime}=1 \mathrm{~kW} / \mathrm{m}^{2}$ for unit heat flux per unit area.

Following [28] define

$$
\mathrm{u}=-\partial \mathrm{T} / \partial \mathrm{z}+(\mathrm{h} / \mathrm{k}) \mathrm{T}
$$

$u$ must satisfy the boundary conditions

$$
\begin{aligned}
& u=0 \text { for } t=0 \text { and all } z>0 \\
& u=\dot{q}^{\prime \prime} / k \text { for } z=0 \text { and all } t>0
\end{aligned}
$$

$u$ may be written directly from [28], section 2.5, equation 1 .

$$
u=\frac{1}{k} \frac{2}{\sqrt{\pi}} \int_{x / 2}^{\infty} \dot{q}^{\prime \prime}\left(t-x^{2} / 4 \alpha \mu^{2}\right) e^{-\mu^{2}} d \mu
$$

Equation A3.1 is now solved for $T$. We note first the adjoint equation ( $u-0$ in $A 3.1$ ) has the solution

$$
\mathrm{v}=\mathrm{C}_{1} \exp (\mathrm{hz} / \mathrm{k})
$$

Then

$$
\begin{aligned}
& -v \partial T / \partial z+(h / k) v T+T \partial v / \partial z-(h / k) T v=v u \\
& -\partial(T / v) / \partial z=u / v \\
& T=C 2\left[C_{1} \exp (h z / k)\right]+\int_{0}^{\infty} u(z+\eta) \exp -(h \eta / k) d \eta
\end{aligned}
$$

The constant $C_{2}$ must be zero if the solution is to be regular as $z$ becomes very large. After substituting the previously obtained value for $u$, considerable algebra yields

$$
\mathrm{T}=\frac{1}{\sqrt{k}} \sqrt{\frac{\alpha}{\pi}} \int_{0}^{t} \dot{\mathrm{q}}^{\prime \prime}(t-s)[1-f(z+\sqrt{\alpha} \mathrm{sh} / \mathrm{k})] \mathrm{e}^{-\left(\mathrm{z}^{2} / 4 \alpha \mathrm{s}\right)} \frac{1}{\sqrt{\mathrm{s}}} \mathrm{ds}
$$


where

$$
f(p)=\sqrt{\pi} p \exp \left(p^{2}\right) \operatorname{erfc}(p)
$$

The terms under the integral in A3.2 have the following meanings. The first term, $\dot{q}^{\prime \prime}(t-s)$, is the radiant heat input to the surface. The second group of terms [1 - f], are, the 1: the result of heating in the absence of surface heat loss, and the $f$ : the decreased rate of heating occasioned by this loss.

The exponential term represents the heating in depth of the solid. When calculating the surface temperature (our present interest), $z=0$ and the exponential term is 1. Finally, note that, if $\dot{q} "$ is constant, the result is the well known square-root behavior of a solid impulsively heated.

Comparing A3.2 with 1 we see that

$$
K(s)=\sqrt{\frac{\alpha}{\pi k}}[1-f(\sqrt{\alpha} \operatorname{sh} / k)] / \sqrt{s}
$$

Section A3.2: Further development of equation 1

Next equation 4 of the main text is to be substituted in equation A3.2 (with $z=0$ ), but first, anticipating exponential growth, the following substitutions are made

$$
\begin{aligned}
& r=r_{0} \exp [\beta(t-s)] \\
& x=r_{0} \exp [\beta t]
\end{aligned}
$$

and

$$
R=x \sqrt{1+\exp (-2 \beta s)}
$$

Here $\beta$ is the exponential growth rate. We note in passing that, if the exponential assumption is consistent, the resulting expression, to be presented below, will be an algebraic equation for $\beta$ with coefficients independent of $x$ and $t$.

The result of these substitutions for the $\dot{q}^{\prime \prime}(t-s)$ of equation 4 is

$$
\dot{q}^{\prime \prime}(t-s)=\left(Q_{f} " / 4\right)[1 / \sqrt{1+\exp (2 \beta s)}]^{3}
$$

Upon substituting this in $\mathrm{A} 3.2$ and observing that, if both sides of the equation are multiplied by $h$, the result can be written

$$
A=G I_{1}-G^{2} I_{2}
$$

where

$$
\mathrm{G}=\mathrm{h} / \sqrt{\mathrm{k} \rho \mathrm{c} \beta}
$$


and

$$
\begin{aligned}
& I_{1}=\int_{0}^{\ln \left(x / r_{0}\right)}\left(1 / \sqrt{1+\exp (2 s))^{3}} d s / \sqrt{s}\right. \\
& I_{2}=\int_{0}^{\ln \left(x / r_{0}\right)} \sqrt{\pi}(1 / \sqrt{1+\exp (2 s)})^{3} e^{G^{2} s} \operatorname{erfc}(G \sqrt{s}) d s \\
& A=4 \sqrt{\pi} h\left(T_{i}-T_{0}\right) / \dot{Q}_{f} "
\end{aligned}
$$

Examination of $I_{1}$ suggests that, for large enough values of its upper limit, it should be a constant. Numerical integration of $I_{1}$ (and $I_{2}$ ) shows that $I_{1}$ is within 38 of its asymptotic (large upper limit) value when $\ln \left(x / r_{0}\right)=1$. That is, for fires which have grown to 2.7 times their initial radius. Since, for example, the NBS/Harvard simulation takes the initial radius for a growing fire as about $r_{0}=3 \mathrm{~cm}$, the integrals would be essentially constant for $x=8 \mathrm{~cm}$ or more. $\mathrm{I}_{2}$, however, is somewhat more complex as it depends both on its upper limit and on the value of G. $G$ is the ratio of the heat transfer capability of the surface toward the gas to its capability into the solid. For most materials $G$ is a small number because the gas, even with (linearized) radiation, is a poor heat transfer medium compared to the solid. (For hardboard $G$ ranges from 0.05 to 0.005 [11].) With the upper limit of integration $2.5, \mathrm{I}_{2}$ varies 5.38 as $G$ varies from 0.1 to 0.001 and, with $G=$ $0.01, \mathrm{I}_{2}$ increases 48 when the upper limit is increased indefinitely from 2.5 . The change is 8.38 for an upper limit of 2. Thus, for the expected range of variation of $G, I_{2}$ may be assumed essentially constant for fires at least an order of magnitude larger than their initial size. Finally, if $I_{1}$ and $I_{2}$ are constants, then our assumption of exponential growth is justified since $G$ values calculated from A3.3 are independent of time and, therefore, $\beta$ values are constant. To the extent that $I_{1}$ and $I_{2}$ deviate from constants, so the fire growth will deviate from exponential. In fact, exponential growth is not to be expected for the early phases of fire growth. ${ }^{3}$

${ }^{3}$ Unpublished data of $R$. Land, Harvard University, gives very detailed measurements of $r(t)$ for fires spreading on urethane foam. His data shows that $r(t)$ varies exponentially with time, but only after an initial growth period has past. Although his data is consistent with the small time behavior of the present model, this is fortuitous as the model assumes a turbulent flame, among other things. For Land's small initial fires, laminar, not turbulent flames would be expected. 
The numerical integrations with upper limit 2.5 and $G=0.01$ are

$$
\begin{aligned}
& I_{1}=0.4509 \\
& I_{2}=0.5866
\end{aligned}
$$

When equation $A 3.3$ is solved for $G$, a real $G$ is obtained only if $A$, the left hand side of $A 3.3$, is less than $I_{1}{ }^{2} /\left(4 * I_{2}\right)$. This reflects the fact that, if the surface cooling is sufficient, relative to the fire size, the fuel will never be heated to its ignition temperature and flame spread will not be possible. In fact, we know that flames will not spread on a horizontal piece of wood without more heat than the wood's own flames can supply. In this case, the pyrolysis temperature is about $420^{\circ} \mathrm{C}$ and radiation loss from the surface is quite large. If, however, A3.3 has a real root, then our initial assumption of exponential flame spread is born out except for the initial stages of growth. Note that, at the limit of real flame spread the fire still grows at a finite rate. This is experimentally observed, but the limit flame spread rate given by our formula should not be expected to be correct. Recall that, near extinction, the assumption of one-dimensional heat transfer breaks down. Further, the surface regression behind the slowly moving flame causes the fuel surface to deviate significantly from a horizontal plane. These effects and the local heating around the flame foot invalidate the assumptions of the present model.

The limitations on the flame spread model discussed above suggest that a suitable approximate solution to equation A3.3 would be to assume that the surface heat transfer coefficient, $h$, must not be too large. The result is

$$
\beta=\frac{I}{\sqrt{k \rho c}}\left\{\frac{I_{1}}{4 \sqrt{\pi}}\left[\frac{\dot{Q}_{f}^{\prime \prime}}{\left(T_{i}-T_{0}\right)}-\frac{4 \sqrt{\pi}}{I_{I}^{2}} I_{2} h\right]\right\}^{2}
$$

where

$$
N=4 \sqrt{\pi} I_{2} / I_{1}^{2}=20.46
$$

This is valid provided

$$
N * h * T_{s} \ll \dot{Q}_{f} "
$$

Several improvements on the above model should be considered. In general these lead to fire growth that is not strictly exponential. As a result, more complex analytic methods are needed to find the flame spread velocity. The simplest is based on the observation that the local heat flux just before the flame reaches any given location, $x$, is more important than the behavior at earlier times. Accordingly the integrand of A3.2 is expanded in a Taylor series in the flame spread velocity, $V$. The result of such an expansion will not be discussed here, but some of the additional effects, not included in the above "exponential growth" analysis, will be mentioned. 
In a room fire situation, the heating of non-burning fuel is influenced by radiation from the hot gases trapped in the upper part of the room and from the heated upper walls and ceiling. This radiation is, to a first approximation, independent of $x$ but depends on time. If the spreading fire under consideration is the only fire in the room, this will be heavily dependent on the fire size (and will tend to support exponential growth as a result) but, in general the connection may be quite otherwise. This effect is clearly important to accurate room fire analysis and should be included. It is considered in [11] where its effect suggests that, for our case, it would appear as a correction to $\mathrm{T}_{0}$ in $\mathrm{A} 3.4$.

Also considered in [11] is the effect of the local heating around the flame foot (leading edge). In fact, this is the principal mode of forward heat transfer considered in [11] where it is shown to dominate up-wind flame spread (on a solid). Using approximations similar to [11] this term could also be included. For large "pool" fires it would be a correction, not the major (controlling) term.

A slightly more complex expression than equation 4 is obtained if the approach of deRis in [9] is followed. The flame radiant flux is explicitly expressed as

$$
\dot{\mathrm{Q}}^{\prime \prime} \quad=\sigma \mathrm{T}^{4}\left[1+\sqrt{1+(\mathrm{h} / \mathrm{r})^{2}}\right][1-\exp (-\mathrm{k} 1)]
$$

where $\quad \sigma \mathrm{T}^{4}=$ flame radiative power per unit flame surface area

$\left[1+\sqrt{1+(h / r)^{2}}\right]=$ a flame shape factor (deRis assumes a conical flame)

$[1-\exp (-\mathrm{k} 1)]=$ emissivity. For the assumed conical flame $\ell / r=1.2 /\left[1+\sqrt{1+(h / r)^{2}}\right]$

$R=\sqrt{x^{2}+z^{2}}$ where $z$ is not necessarily equal to $r$

If it is assumed that the flame is adequately represented by a cone and that the cone angle is constant (as is assumed in the Harvard fire models, except for special cases) the area factor would be outside the integral and $z$ would be proportional to $\mathrm{r}$. The emissivity term should be expected inside the integral. as the flame emissivity will change as it grows, for the sizes of most interest. (The equations given earlier would be correct if the emissivity were constant and a good approximation if it were nearly constant during the most recent past). The effect of these changes are that the integral is no longer expressible as a number (for $\beta$ t large, as noted above). Its value depends on the choice of the flame extinction coefficient, $k$. The deviation from exponential growth is not great even when the full deRis analysis is used inside the integral.

For our present purposes, all of the above improvements are somewhat irrelevant (although they would be desirable for inclusion in an improved flame spread expression in the room fire models). Recall that our purpose was to find a more detailed expression for the exponential growth rate of fires, given, a fortiori, that exponential growth was in agreement with observation. 
We have such an expression in A3.4. In this the material dependency is in the "thermal inertia", kpc. Even with all of the above improvements, this will remain, not only as the major material property of interest, but also its functional relation to the entire expression will not change significantly. Thus $A 3.4$ and 5 in the main text, provide a valid basis for correlating experimental data for thermal inertia. In this sense, our purpose is accomplished. 


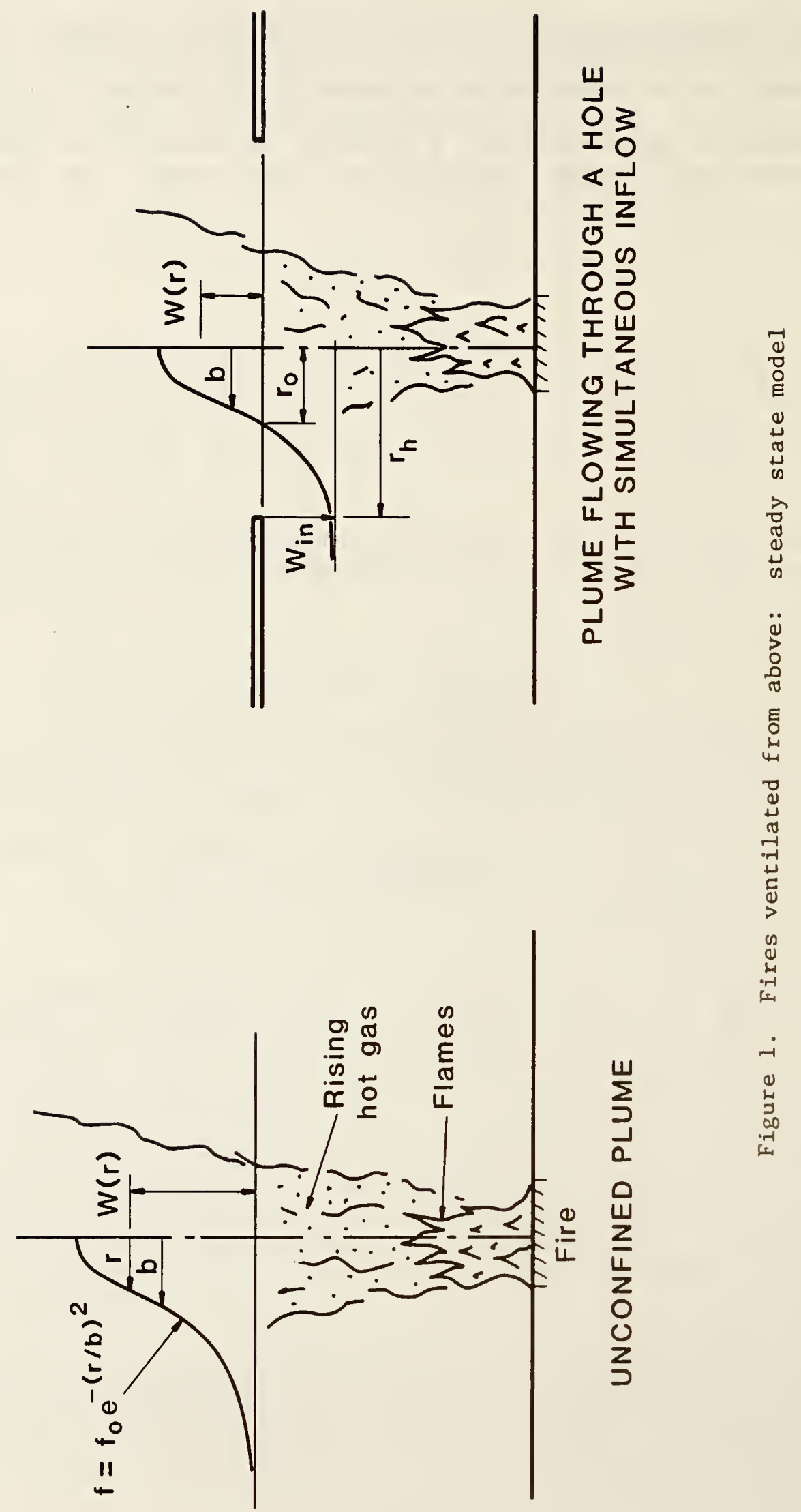




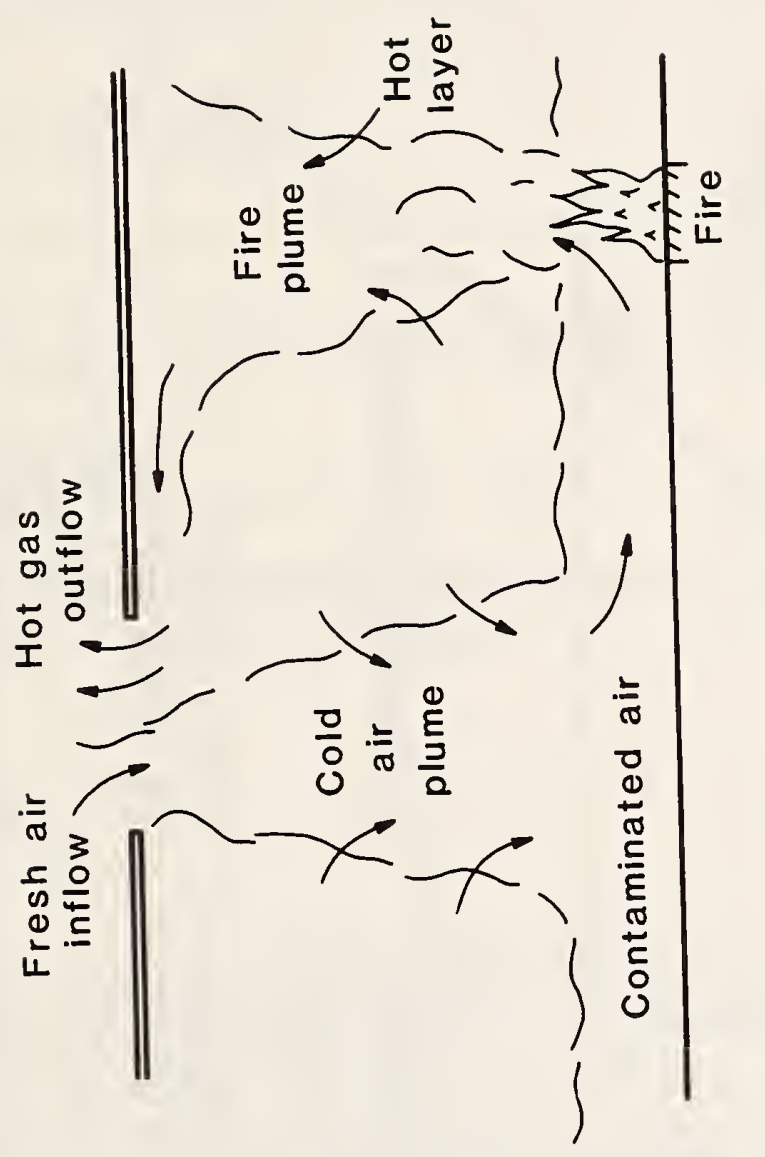

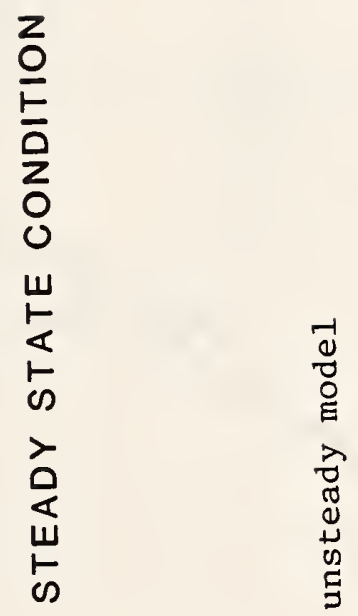

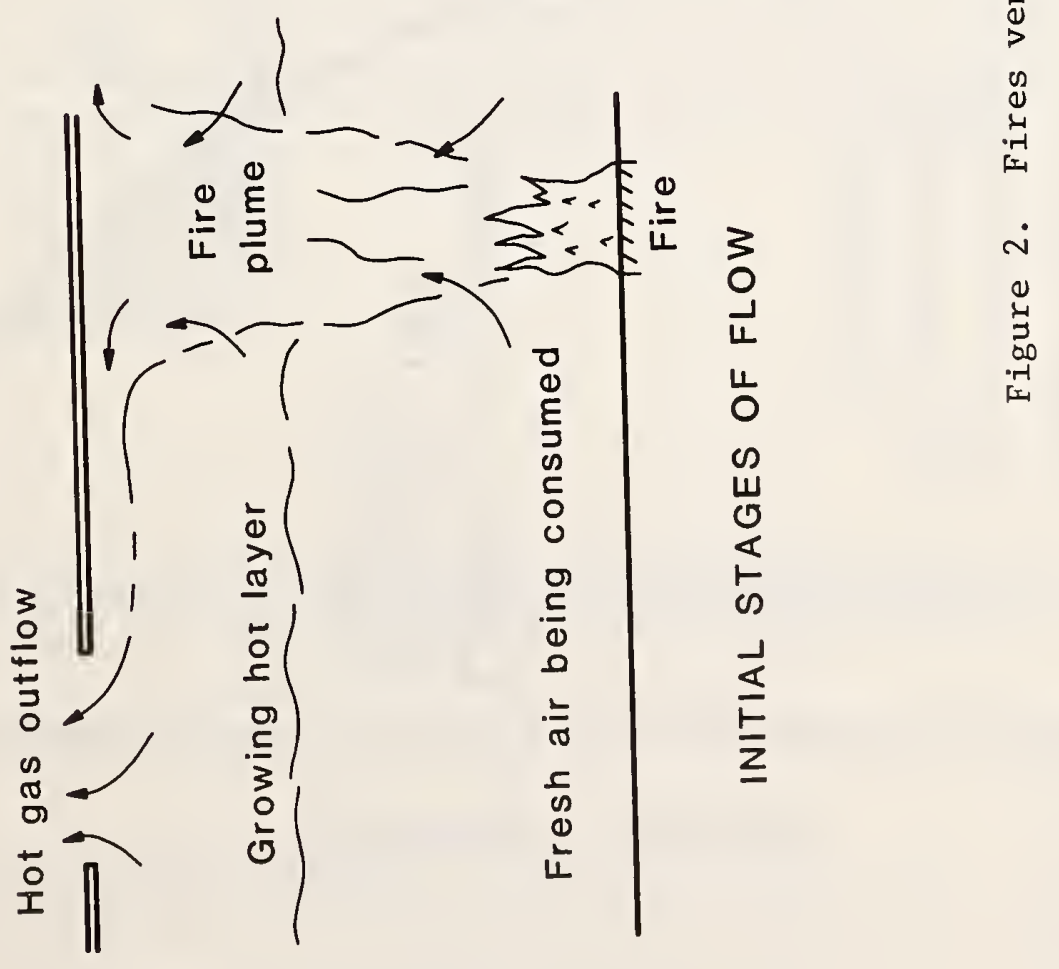




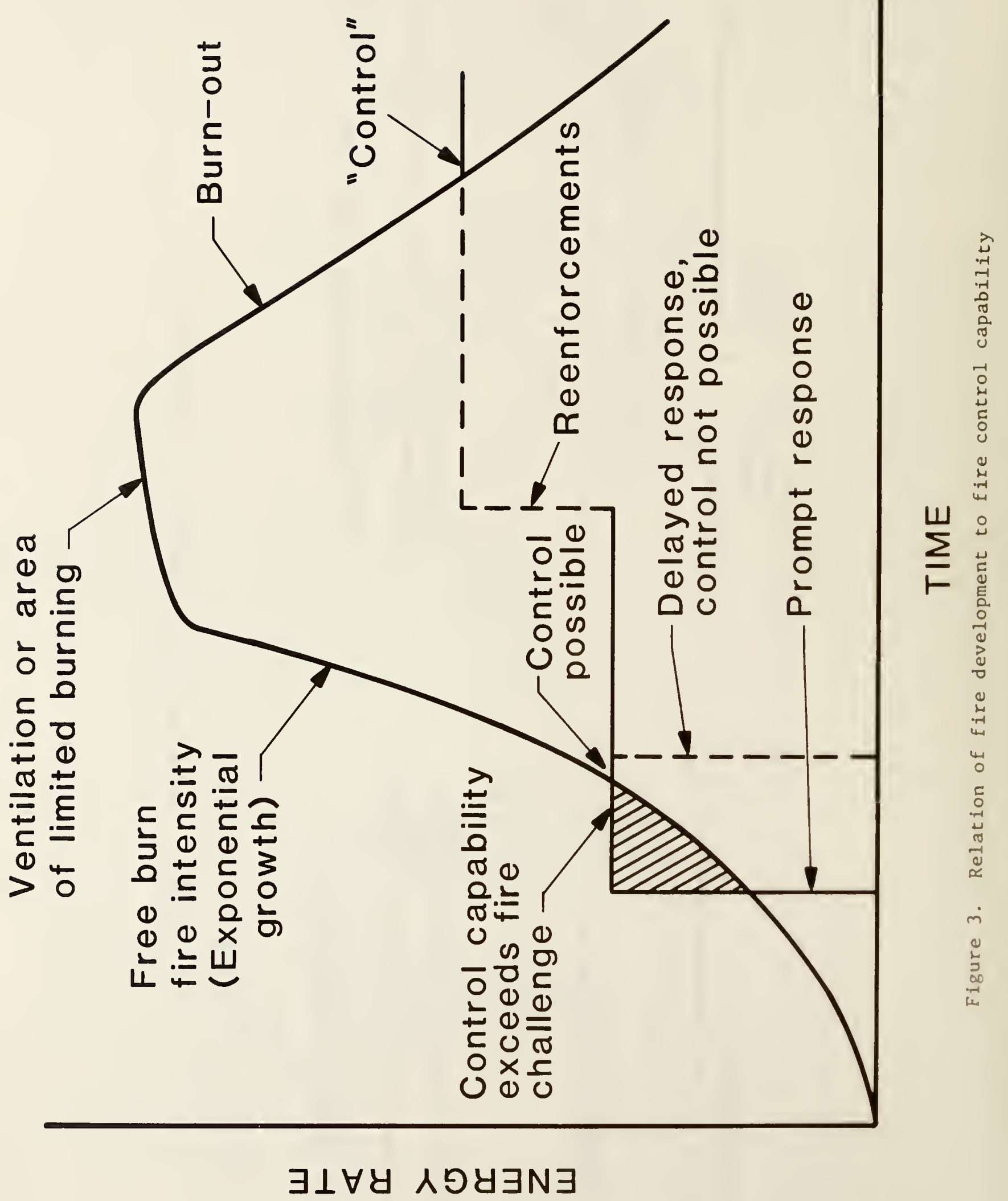


NBS.114A (REV. 2-8C)

U.S. DEPT. OF COMM.

BIBLIOGRAPHIC DATA

SHEET (See in structions)

1. PUBLICATION OR REPORT NO.

NBSIR-86/3451
2. Performing Organ. Report Nod 3. Publication Date

September 1986

4. TITLE AND SUBTITLE

FIRE GROWTH IN COMBAT SHIPS

5. AUTHOR(S)

John A. Rockett

6. PERFORMING ORGANIZATION (If joint or other than NBS, see instructions)

7. Contract Grant No.

MATIONAL BUREAU OF STANDARDS

DEPARTMENT OF COMMERCE

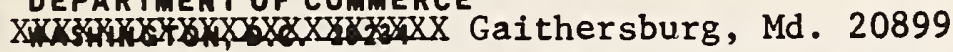

8. Type of Report \& Period Covered

9. SPONSORING ORGANIZATION NAME AND COMPLETE ADDRESS (Street, CIty, Stote, ZIP)

Naval Ship Research \& Development Center

Washington, DC

10. SUPPLEMENTARY NOTES

$\square$ Document describes a computer program; SF-185, FIPS Software Summary, is attached.

11. ABSTRACT (A 200-word or less foctual summory of most significant information. If document includes a significant bibliography or literoture survey. mention it here)

Several enrichments to FIRMOD, the Navy's ship battle damage estimation computer program, are considered. Some proposed enrichments could now be made to good effect, others should only be considered after further experimental work has been done to better define the phenomena involved and the algorithms to be used.

Enrichments recommended for immediate consideration are exponentially growing fires, ingestion by one ventilation system of smoke issuing from other ventilation system exhausts, and smoke transport between spaces served by the same ventilation system. Areas where further experimental work is recommeded before FIRMOD enrichments are considered include fires ventilated primarily from above and buoyant smoke transport up shafts and ladderways.

12. KEY WORDS (Six to twelve entries; alphabetical order; capitalize only proper nomes; and seporote key words by semicolons) fire control; fire growth; fire models; shipboard fires; smoke control; ventilation

13. AVAILABILITY

[X] Unlimited

$\square$ For Official Distribution, Do Not Release to NTIS

$\square$ Order From Superintendent of Documents, U.S. Government Printing Office, Washington, D.C. 20402.

14. NO. OF

PRINTED PAGES

37

15. Price

$\$ 9.95$

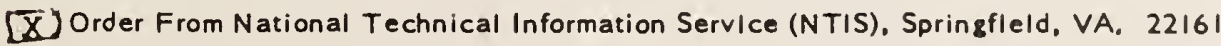




